International Journal of Performability Engineering, Vol. 13, No. 1, January 2017, pp. 87-94

(C) Totem Publisher, Inc., 4625 Stargazer Dr., Plano,

Texas 75024, U.S.A

\title{
Broken Rotor Bar Fault Diagnosis in VFD Driven Induction Motors by an Improved Vibration Monitoring Technique
}

\author{
T.CH. ANIL KUMAR*, GURMEET SINGH and V. N. A. NAIKAN \\ Reliability Engineering Centre, IIT Kharagpur, India
}

(Received on March 8, 2016, Revised on December 13, 2016)

\begin{abstract}
Motor current signature analysis (MCSA) is widely used condition monitoring technique for fault diagnosis of induction motor drives. Application of variable frequency drive (VFD) to operate induction motors is increasing day by day due to their high energy savings compared to conventional speed varying devices like belt drives, gear-boxes etc. One of the limitations of MCSA technique is its inability to detect the presence of incipient level of single BRB fault in VFD driven induction motors at light load conditions up to $15 \%$. Detection of this type of fault using current signatures requires expertise in signal processing techniques. Early detection of BRB fault can avoid the risk of consequent failures in induction motor. In this paper, additional fault frequency features have been proposed to detect the presence of single BRB fault using vibration analysis. The results have been validated at various light load conditions by comparing the vibration signatures of healthy and single BRB state of the motor.
\end{abstract}

Keywords: Induction Motor, MCSA, Vibration Analysis, VFD, Broken Rotor Bar, Load Condition, FFT, Condition Monitoring, Fault Diagnostics

\section{Introduction}

Induction motors are widely used as prime-movers in industries and are operated continuously under mechanical, thermal and electrical stresses which cause failures. Various surveys are conducted on different types of failures observed in motor: bearing related ( $41 \%$ to $75 \%$ ), winding related ( $2 \%$ to $37 \%$ ), rotor related (1\% to $10 \%$ ) and others (2\% to 38\%) [1]. Hence, health assessment of motors plays a significant role in improving their availability. Condition monitoring (CM) not only assess the health state of the motor but also reduces its downtime due to minimization of sudden failures. Various $\mathrm{CM}$ techniques such as vibration analysis, motor current signature analysis (MCSA), infrared thermography etc. are applied for motor fault diagnostics.

It shows that majority of failures observed in motors are bearing and windings related. Even though broken rotor bar shares very small percentage of failures, if unattended can cause further damage to motor windings leading to secondary failures. A brief report on root cause analysis of stator and rotor failures have been analysed in squirrel cage induction motors [2]. Among these techniques, vibration analysis is widely used technique for bearing related faults in an induction motor. However, MCSA is widely used for stator and rotor related problems [3]. One of the limitations of MCSA technique is difficulty in the detection of the presence of single broken rotor bar (BRB) fault in induction motors at light load conditions due to weak modulation of supply current frequency with BRB fault frequency and the problem even perishes when it is fed

*Corresponding author's email: aniltulluri.1983@iitkgp.ac.in 
by an inverter drive or variable frequency drive (VFD) [4]. This is due to the additional noise by VFD in supply frequency. On other hand, vibration monitoring is found to be effective in detecting any subsequent change in the state of the motor [5]. Effect of operating load conditions on motor current and vibration features are well addressed in [6].

Various current based signal processing techniques are used to detect the presence of broken rotor bar faults at light load conditions such as higher order spectrums [7], Hilbert transform (HT) [8], empirical mode decomposition (EMD), ensembled empirical mode decomposition (EEMD) [9], discrete wavelet transform (DWT) [3], multiple signal classification (MUSIC) analysis [4] etc. which requires expertise in selection of appropriate size for auto-correlation matrix for signal information evaluation [10].

Vibration spectrum has also been used for broken rotor bar fault detection at by the presence of peak at frequency component as per equation (1) [11].

$$
f_{b r b}=f_{\text {rbpf }} \pm 2 * f
$$

where, $f_{b r b}$ : broken rotor bar fault frequency, $f_{r b p f}$ : rotor bar pass frequency , $f$ : supply or line frequency.

Rotor bar pass frequency $\left(f_{\text {rbpf }}\right)$ is given by equation (2),

$$
f_{\text {rbpf }}=\frac{N * f}{p}
$$

where, $N$ : no. of rotor bars and $p:$ no. of pole pairs.

DWT has been applied on vibration signals at various load conditions for detection of BRB fault [12]. A comparative study has been carried for BRB detection at different load conditions using short time fourier transform (STFT), morlet wavelet analysis and MUSIC on transient vibration signals during start-up of induction motors [13] . Wavelet analysis on axial vibrations of double squirrel cage induction motors for effective detection of BRB fault is presented by [14]. The above works are proposed for the detection of BRB in induction motors driven by direct online supply (D.O.L). Moreover, the work carried is around the changes observed at the side-band amplitudes of rotational frequency at no load, half - load and full - load conditions of the induction motor. There are no insights regarding the changes in vibration spectrum observed in the presence of BRB fault in VFD driven induction motors. Therefore, this paper explores the possibility of identification of any other fault frequency component in vibration spectrum for more effective fault diagnosis of BRB in VFD driven induction motors.

Further, the paper is organised as follows: section 2 discusses the proposed methodology and why additional fault frequency features are needed. The section 3 presents the details of experimental set-up and procedure followed to validate the results of proposed methodology for detection of single BRB fault in motor driven by VFD. Section 4 presents brief discussion on results obtained from the experiments and section 5 conclusions. 


\section{Proposed Methodology}

In general, induction motors in industries are operated either D.O.L or through VFD. Application of VFD has increased recently due to their high energy efficiency when motors are to be operated at variable speeds in industries like textile, conveyors, food processing etc. Generally, in VFD driven motor drives, supply frequency ( $f$ ) gets modulated with high carrier frequency $\left(f_{c}\right)$. From the experimental investigations, it has been found that the rise of vibration amplitudes at frequencies proposed in equation (1) is less in case of incipient level of single BRB fault when compared to healthy motor. So, it makes very difficult to take the decision whether BRB is present. In the case of VFD driven motors along with supply frequency there is carrier frequency and what are the subsequent changes that can be observed in the vicinity of ' $f_{c}$ ', fundamental frequency ' $f_{r}$ ' and rotor bar pass frequency ' $f_{r b p f}$ ' in the presence of incipient level of single BRB fault have not been addressed in the literature. This has motivated the authors to search for new BRB fault frequency near ' $f_{c}$ ' that can detect the presence of incipient level of BRB fault for more effective fault diagnosis.

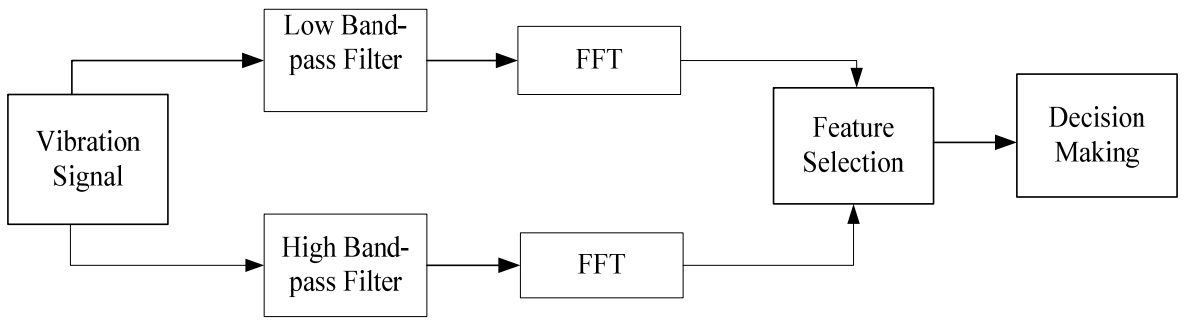

Fig 1.: Proposed Methodology

For achieving this, an algorithm is proposed as follows and is shown in Fig 1:

a. Vibration signals in radial direction are collected at a sampling rate at least 3 to 4 times of the carrier frequency $\left(f_{c}\right)$ of the VFD.

b. The recorded vibration signal is passed through two band-pass filters. One Low band-pass filter within frequency range $\left(f_{r b p f} \pm 3 f\right)$ and other one high bandpass filter within frequency range $\left(f_{c}+f_{r b p f} \pm 4 f\right)$.

c. Fast Fourier Transform (FFT) is carried on the both filtered signals.

d. Proposed Features are selected from (c) and then decision making is done.

The next section deals with the details of experimental set-up needed to find out additional BRB fault frequency and to validate the fore-mentioned methodology

\section{Experimental Set-up}

Experiments are carried on 5-hp, 4-pole, 3-phase induction motor with 26 rotor bars coupled to a generator. Load on the motor is applied through by varying resistive loads on generator. The motor is driven by VFD drive with carrier frequency ' $4 \mathrm{KHz}$ ' at supply 
frequency of $50 \mathrm{~Hz}$. Therefore, the rotor bar pass frequency is at $650 \mathrm{~Hz}$ as per equation (2). Fig 2 shows the single BRB fault rotor.

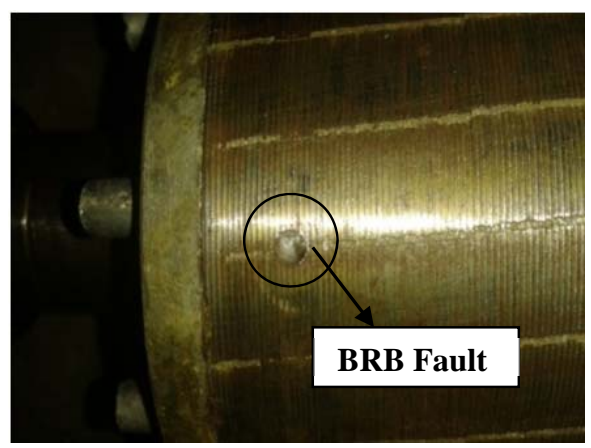

Fig 2.: Single BRB fault rotor

Using the above set-up, the tests have been performed as per procedure stated below:

i. Radial Vibration signatures have been collected at a sampling rate of $20 \mathrm{KS} / \mathrm{s}$ for duration of ' 10 s' in each case.

ii. First, samples of vibration signatures of the healthy motor are collected at no load condition.

iii. Step ' $\mathrm{ii}$ ' is continued for load conditions 5\%, $10 \%, 15 \%$.

iv. Now, the healthy rotor of the motor is replaced by single BRB fault rotor.

v. Steps 'i' - 'iii' are repeated in the case of BRB fault condition.

After the collection of the vibration signals at all load conditions for both the healthy and single BRB fault motor the samples are then post processed for further analysis using MATLAB 2014b. Results and discussions are discussed in following section

\section{Results and Discussions}

To detect the presence of single BRB fault, first the normalized amplitudes with respect to rotational frequency amplitude present at fault frequency represented by equation (1) are compared at light load conditions for healthy and single BRB fault state of the motor in frequency range $(650 \pm 100) \mathrm{Hz}$ as per the available literature. Table 1 represents the average normalized value of the frequency amplitudes of the samples collected.

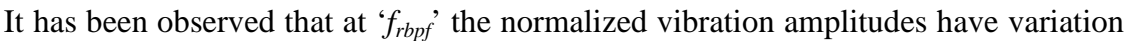
(from 0.018 to 0.039 ) \% up to $15 \%$ load condition in healthy state to that of fluctuations in BRB fault state (from 0.051 to 0.079$) \%$. At frequency ' $\left(f_{\text {rbpf }}+2 f\right)$ )', normalized vibration amplitudes are varied (from 0.642 to 1.026 ) \% in healthy state to (3.018 to 4.959 ) \% in the presence of BRB fault without any correlation to load condition. But, one can observe rise in normalized amplitude at a particular load condition. The variations observed in normalized amplitudes at frequency ' $\left(f_{\text {rbpf }}-2 f\right)$ ' are not significant enough to take conclusive decision. From above discussion, it is clear that no conclusive decision about the presence of single BRB can be made using the available methods. In other words, 
there is a need for finding additional fault frequency features for detection of incipient level single BRB fault more effectively in case of VFD driven motors.

Table 1: Vibration Amplitudes of healthy and single BRB fault as per literature

\begin{tabular}{|c|c|c|c|c|c|c|c|c|}
\hline \multirow[b]{2}{*}{$\begin{array}{c}\text { LOAD } \\
\text { (\%) }\end{array}$} & \multicolumn{2}{|c|}{$f_{r}\left(m / s^{2}\right)$} & \multicolumn{2}{|c|}{$\left(f_{\text {rbpf }} / f_{r}\right) * 100$} & \multicolumn{2}{|c|}{$\left[\left(f_{r b p f}+2 f\right) / f_{r}\right] * 100$} & \multicolumn{2}{|c|}{$\left[\left(f_{r b p f}-2 f\right) / f_{r}\right] * 100$} \\
\hline & Healthy & $\begin{array}{l}\text { One } \\
\text { BRB } \\
\end{array}$ & Healthy & $\begin{array}{l}\text { One } \\
\text { BRB } \\
\end{array}$ & Healthy & $\begin{array}{l}\text { One } \\
\text { BRB } \\
\end{array}$ & Healthy & $\begin{array}{l}\text { One } \\
\text { BRB } \\
\end{array}$ \\
\hline 0 & 3.67067 & 2.44813 & 0.018 & 0.051 & 0.642 & 3.018 & 1.164 & 1.397 \\
\hline 5 & 2.82207 & 2.31153 & 0.020 & 0.061 & 0.475 & 3.824 & 1.486 & 1.517 \\
\hline 10 & 2.57473 & 2.07773 & 0.022 & 0.052 & 0.454 & 3.556 & 1.660 & 1.646 \\
\hline 15 & 2.29473 & 1.78247 & 0.039 & 0.079 & 1.026 & 4.959 & 1.828 & 1.967 \\
\hline
\end{tabular}

Table 2 represents the normalized vibration amplitudes for both healthy and BRB fault states in the vicinity of carrier frequency zone $(4650 \pm 200) \mathrm{Hz}$ of vibration spectrum as per the proposed methodology. Time domain representation of both LBPF and HBPF are given in the Fig A1 of Appendix A. High amplitude in vibration can be clearly observed in the HBPF signal indicating the presence of BRB fault. Vibration amplitudes at different frequencies are extracted from the vibration spectrum and are presented in this table.

Table 2: Proposed Vibration features for detection of single BRB in motor

\begin{tabular}{|c|c|c|c|c|c|c|c|c|}
\hline \multirow{2}{*}{$\begin{array}{l}\text { LOAD } \\
(\%)\end{array}$} & \multicolumn{2}{|c|}{$\left[\left(f_{c}+f_{\text {rbp }}+f\right) / f_{r}\right] * 100$} & \multicolumn{2}{|c|}{$\left[\left(f_{c}+f_{\text {rbpf }}-f\right) / f_{r}\right] * 100$} & \multicolumn{2}{|c|}{$\begin{array}{c}{\left[\left(f_{c}+f_{r b p f}+3 f\right) /\right.} \\
f_{r}{ }^{*} * 100 \\
\end{array}$} & \multicolumn{2}{|c|}{$\begin{array}{c}{\left[\left(f_{c}+f_{r b p f}-3 f\right) /\right.} \\
\left.f_{r}\right] * 100\end{array}$} \\
\hline & Healthy & $\begin{array}{l}\text { One } \\
\text { BRB }\end{array}$ & Healthy & $\begin{array}{l}\text { One } \\
\text { BRB }\end{array}$ & Healthy & $\begin{array}{l}\text { One } \\
\text { BRB }\end{array}$ & Healthy & $\begin{array}{l}\text { One } \\
\text { BRB }\end{array}$ \\
\hline 0 & 69.746 & 161.277 & 6.308 & 24.831 & 42.437 & 40.532 & 7.828 & 28.582 \\
\hline 5 & 106.886 & 185.675 & 9.128 & 26.043 & 69.814 & 65.576 & 12.515 & 27.429 \\
\hline 10 & 99.433 & 190.028 & 8.994 & 29.257 & 60.501 & 47.758 & 11.160 & 33.677 \\
\hline 15 & 131.449 & 240.786 & 11.225 & 33.773 & 85.857 & 85.039 & 15.391 & 35.571 \\
\hline
\end{tabular}

At frequency ' $\left(f_{c}+f_{\text {rbpf }}+f\right)$ ', normalized vibration amplitudes are increased (from 69.746 to 131.449$) \%$ in healthy state to (161.277 to 240.786$) \%$ in the presence of BRB fault. At frequency ' $\left(f_{c}+f_{\text {rbpf }}-f\right)$ ', normalized vibration amplitudes have been increased (from 6.308 to 11.225 ) \% in healthy state to (24.831 to 33.773 ) \% in the presence of BRB fault. A peculiar trend has been observed between new proposed fault frequency amplitudes ' $\left(f_{c}+f_{\text {rbpf }} \pm f\right)$ ' with strong correlation with rotational frequency amplitude and load condition. At frequency ' $\left(f_{c}+f_{r b p f}+3 f\right)$ ' no significant changes in normalized vibration amplitudes are observed compared to that corresponding to ' $\left(f_{c}+f_{\text {rbpf }} \pm f\right)$ '. At frequency ' $\left(f_{c}+f_{r b p f}-3 f\right)$ ', normalized vibration amplitudes have been increased (from 7.828 to 15.391 ) \% in healthy state to (28.582 to 35.571 ) \% in the presence of BRB fault but without any trend towards load conditions.

Maximum vibration amplitudes are observed at frequency ' $\left(f_{c}+f_{r b p f} \pm f\right)$ ' compared to other frequencies ' $\left(f_{c}+f_{\text {rbpf }} \pm 3 f\right)$ '. Percentage changes in amplitudes of vibration from healthy state to BRB state are also highest at these new frequencies. It has also been observed that higher change in normalized vibration amplitude at new fault frequency 
represented in equation (3) have been noticed when compared to that of fault frequency computed using equation (1). (refer Fig A2. in Appendix: A)

$$
f_{b r b}{ }^{\prime}=\left(f_{c}+f_{r b p f}\right) \pm f
$$

From the above discussions, it is clear that the proposed fault frequency can effectively detect the presence of single BRB fault in the motor for light load conditions. Therefore, for a motor driven by VFD it is better to observe the rise in vibration amplitudes at the proposed fault frequency for effective fault diagnosis of incipient level of BRB fault at light load conditions.

\section{Conclusion}

Present work shows how vibration monitoring is beneficial in detection of single BRB fault in VFD driven induction motors when operated at light load conditions. Additional fault frequency features of vibrations helps the industrial personnel in decision making. Rise in the vibration amplitudes at proposed features (i.e. $\left[\left(f_{c}+f_{r b p f}\right) \pm f\right]$ ) is very strong when compared to the amplitude rise at the existing fault frequencies stated in the literature. The proposed frequencies are not only able to detect the presence of single BRB fault and also have a strong correlation with increase in load condition of the motor when compared to the existing features (i.e. $f_{r b p f} \pm 2 * f$ ). This aids as an additional advantage to the diagnostics personnel to address single BRB fault of the VFD driven induction motors rather than relying only on the fault frequency available in the literature.

\section{References}

[1]. Tavner, PJ. Review of Condition Monitoring of Rotating Electrical Machines. IET Electric Power Applications. 2008 Jul;2(4):215-47.

[2]. Bonnett, A. H., and G. C. Soukup. Cause and Analysis of Stator and Rotor Failures in Three-Phase Squirrel-Cage Induction Motors. IEEE Trans. Ind. Appl., 1992 Aug;28(4):921-937.

[3]. Douglas, H., P. Pillay, and A. Ziarani. Detection of Broken Rotor Bars in Induction Motors Using Wavelet Analysis. In IEEE Electric Machines and Drives Conference, 2003 Jun 1; 2: 923-928.

[4]. A. Naha, A. K. Samanta, A. Routray, and A. K. Deb. A Method for Detecting HalfBroken Rotor Bar in Lightly Loaded Induction Motors Using Current. IEEE Trans. Instrum. Meas., 2016 July; 65(7): 1614-1625.

[5]. Kumar, T. C. A., G. Singh, and V. Naikan. Effectiveness of Vibration Monitoring in the Health Assessment of Induction Motor. Int. Journal of Prognostic and Health Management, 2015;6(Special Issue Uncertainty in PHM, 007):9.

[6]. Obaid, R. R. and T. G. Habetler. Effect of Load On Detecting Mechanical Faults in Small Induction Motors. In Diagnostics for Electric Machines, Power Electronics and Drives, 2003. SDEMPED 2003. 4th IEEE International Symposium on 2003 Aug 24 (pp. 307-311).

[7]. Liang, B., S. D. Iwnicki, and Y. Zhao. Application of Power Spectrum, Cepstrum, Higher Order Spectrum and Neural Network Analyses for Induction Motor Fault Diagnosis. Mech. Syst. Signal Process., 2013; 39(1-2):342-360.

[8]. Laala, W., S.E. Zouzou, and S. Guedidi. Induction Motor Broken Rotor Bars Detection Using Fuzzy Logic: Experimental Research. Int. J. Syst. Assur. Eng. Manag., 2014;5(3):329-336.

[9]. Wang, J., R. X. Gao, and R. Yan. Broken-Rotor-Bar Diagnosis for Induction Motors. In Journal of Physics: Conference Series 2011 (Vol. 305, No. 1, p. 012026). IOP 
Publishing.

[10]. Naha, A., A. K. Samanta, A. Routray, and A. K. Deb. Determining Autocorrelation Matrix Size and Sampling Frequency for MUSIC Algorithm. IEEE Signal Process. Lett., 2015; 22(8) :1016-1020.

[11]. Kanovic, Z., D. Matic, Z. Jelicic, M. Rapaic, B. Jakovljevic, and M. Kapetina. Induction Motor Broken Rotor Bar Detection Using Vibration Analysis-A Case Study. In Diagnostics for Electric Machines, Power Electronics and Drives (SDEMPED), 2013 9th IEEE International Symposium on 2013 Aug 27 (pp. 64-68). IEEE.

[12]. Rangel-Magdaleno, J., H. Peregrina-Barreto, J. Ramirez-Cortes, R. Morales-Caporal, and I. Cruz-Vega. Vibration Analysis of Partially Damaged Rotor Bar in Induction Motor under Different Load Condition Using DWT. Shock and Vibration. 2016: 1-11.

[13]. Delgado-Arredondo P.A., A. Garcia-Perez, D. Morinigo-Sotelo, R.A. Osornio-Rios, J.G. Avina-Cervantes, H. Rostro-Gonzalez, and R.D. Romero-Troncoso. Comparative Study of Time-Frequency Decomposition Techniques for Fault Detection in Induction Motors Using Vibration Analysis During Startup Transient. Shock and Vibration. 2015 Jul 9; 2015.

[14]. Miceli, R., Y. Gritli, A. Di Tommaso, F. Filippetti, and C. Rossi. Vibration Signature Analysis for Monitoring Rotor Broken Bar in Double Squirrel Cage Induction Motors Based On Wavelet Analysis. COMPEL: The International Journal for Computation and Mathematics in Electrical and Electronic Engineering. 2014 Aug 26; 33(5):1625-41.

\section{Appendix: A}
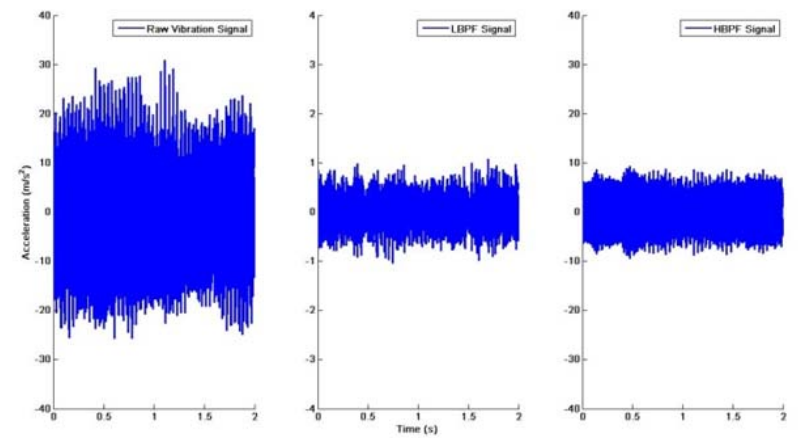

(a)
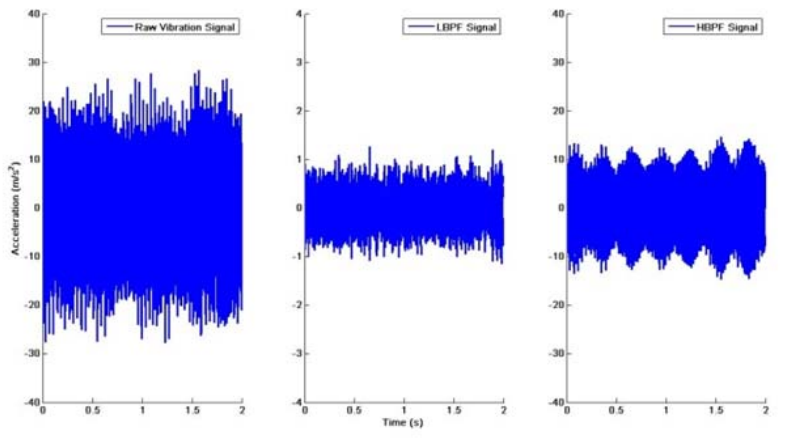

(b)

Fig A1: Vibration Signal at 5\% Load Condition in a) Healthy state and b) BRB fault state 


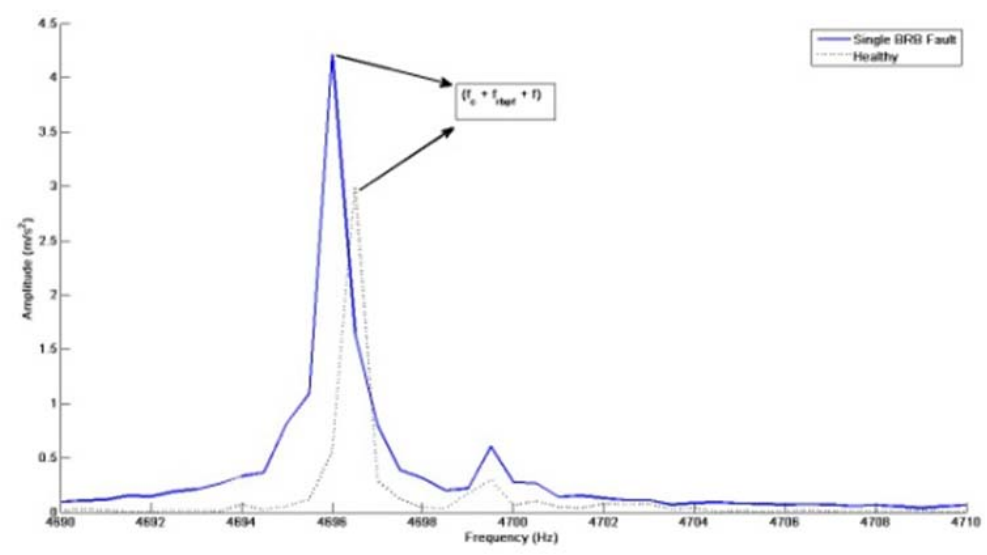

Fig A2: Rise in Vibration Amplitude at $5 \%$ Load condition at $\left(f_{c}+f_{r b p f}\right)+f$

T. CH. Anil Kumar is an Assistant Professor in the Department of Mechanical Engineering of Vignan University, Vadlamudi since 2010 and currently pursuing Ph.D from Reliability Engineering Centre, IIT Kharagpur, India under Quality Improvement Program (QIP). He had completed his Masters of Engineering in Advanced Design \& Manufacturing from Osmania University, Hyderabad in the year 2008. He worked as Project Assistant (Level-III) for two years in SERC, CSIR Campus at Chennai. His research interests are Condition based maintenance, Machinery fault diagnosis, Vibration Monitoring, Statistical Process Control and Reliability Analysis of Systems.

Gurmeet Singh is currently pursuing $\mathrm{PhD}$ from Reliability Engineering Centre, IIT Kharagpur. He completed his Masters in Condition Monitoring Control and Protection of Electrical Apparatus from NIT Hamirpur in the year 2013. His research interests include Condition Monitoring, Fault diagnosis, Asset Management and Automation.

V.N.A. Naikan is currently a joint Professor on Industrial and Systems Engineering Professor and Head of the Reliability Engineering at the Indian Institute of Technology Kharagpur, India. His research interests include quality and reliability engineering, condition monitoring, and simulation. He has published more than 120 papers, a book, and two book chapters. He is member of editorial and advisory board of many international journals. 